\title{
Surface turbulent fluxes over pack ice inferred from TOVS observations
}

\author{
R.W. Lindsay, ${ }^{1}$ J. A. Francis, ${ }^{2}$ P. O. G. Persson ${ }^{3}$ D. A. Rothrock, ${ }^{1}$ A. J. Schweiger ${ }^{1}$ \\ ${ }^{\prime}$ Polar Science Center, Applied Physics Laboratory, University of Washington, 1013 . NE 40th Street, Seattle, WA 98105, U.S.A. \\ ${ }^{2}$ Institute of Marine and Coastal Sciences, P.O. Box 231, Rutgers University, New Brunswick, Nf 08903-0231, U.S.A. \\ ${ }^{3}$ Cooperative Institute for Research in Environmental Sciences, University of Colorado, Boulder, CO 80303, U.S.A.
}

\begin{abstract}
A one-dimensional, atmospheric boundary-layer model is coupled to a thermodynamic ice model to estimate the surface turbulent fluxes over thick sea ice. The principal forcing parameters in this time-dependent model are the air temperature, humidity, and wind speed at a specified level (either at $2 \mathrm{~m}$ or at $850 \mathrm{mb}$ ) and the downwelling surface radiative fluxes. The free parameters are the air temperature, humidity, and wind-speed profiles below the specified level, the surface skin temperature and icetemperature profile, and the surface turbulent fluxes. The goal is to determine how well we can estimate the turbulent surface heat and momentum fluxes using forcing parameters from atmospheric temperatures and radiative fluxes retrieved from the TIROS-N Operational Vertical Sounder (TOVS) data.

Meteorological observations from the Lead Experiment (LeadEx, April 1992) ice camp are used to validate turbulent fluxes computed with the surface observations, and the results are used to compare with estimates based on radiosonde observations or with estimates based on TOVS data. We find that the TOVS-based estimates of the stress are significantly more accurate than those found with a constant geostrophic drag coefficient, with a root mean square error about half as large. This improvement is due to stratification effects included in the boundary-layer model. The errors in the sensible heat flux estimates, however, are large compared to the small mean values observed during the field experiment.
\end{abstract}

\section{INTRODUCTION}

The surface fluxes of radiation, sensible and latent heat and momentum are important links between the atmosphere and the ice. Over the polar ice pack there are few surfacebased measurements of these qualities, and the measurements that do exist are for isolated points and are of relatively short duration. Our understanding of the Arctic climate and our ability to predict the weather would be improved with accurate and timely estimates of these fluxes over the entire Arctic Basin. Satellite observations hold some promise of determining these fluxes with sufficient accuracy. In this paper we explore the possibility of estimating surface fluxes of sensible heat and momentum using the TIROS Operational Vertical Sounder (TOVS) on the National Oceanic and Atmospheric Administration (NOAA) series of polar-orbiting satellites. Information retrieved from TOVS data has tremendous potential for studies of energy transfer and atmospheric dynamics over sea ice where conventional data are sparse. This rich source has only begun to be tapped. Francis (1994), for example, uses retrievals to investigate the advection of heat from lower latitudes into and within the Arctic basin, and data from TOVS have also been used to estimate Arctic surface radiation fluxes (Schweiger and Key, 1997).

Large-scale models of sea ice require inputs of geostrophic wind, downwelling shortwave and longwave fluxes and surface air temperature. Downwelling shortwave and longwave fluxes are traditionally computed using simple parameterizations based on air temperature, cloud fraction and humidity. Questionable climatologies or data from poorly validated numerical weather-prediction models are frequently used for these inputs. Turbulent exchange of heat is specified using bulk formulae with a surface (skin) temperature determined from a surface energy-balance equation. A constant geostrophic drag coefficient is used to determine the ice stress, ignoring changes in the boundarylayer stratification that can have important ramifications for the actual stress (Overland and Davidson, 1992).

Our approach to the problem of estimating the turbulent fluxes using satellite data is to model temperature profiles in the ice and the atmosphere over time, and to determine within the model the required sensible heat and momentum fluxes needed to maintain the surface energy balance. We use observations from the April 1992 Lead Experiment (LeadEx) ice camp to verify the results.

The numerical experiments described below demonstrate a simple one-dimensional (1-D) thermodynamic seaice model that is driven by input variables first derived from surface-based observations and then derived from satellites. The modeled atmospheric profiles of temperature and wind are allowed to vary in time so the surface stress can respond to the changing stratification of the boundary layer. The model is used to compute turbulent fluxes in a series of three experiments.

(a) Experiment 1: surface forcing. The first experiment is 
designed to establish a baseline for comparison with the other two experiments. It uses surface-based observations only and does not include a boundary-layer model. The surface turbulent fluxes calculated in this model are compared to surface measurements. The forcing parameters are surface-observed air temperature, humidity, winds for a height of $2 \mathrm{~m}$, and downwelling shortwave and longwave radiative fluxes. The free parameters are skin temperature, ice-temperature profile and surface turbulent fluxes.

(b) Experiment 2: radiosonde forcing. The second experiment is designed to show that the boundary-layer portion of the model works correctly. The forcing parameters are radiosonde data (temperature, humidity and wind vector) from the $850 \mathrm{mb}$ level and surface-observed downwelling radiative fluxes. The free parameters are the same as those in experiment 1 , plus boundary-layer $(850 \mathrm{mb}$ to the surface) profiles of air temperature, humidity and wind vector.

(c) Experiment 3: TOVS forcing. The third experiment is designed to show the utility of satellite-based observations. The forcing parameters are the $850 \mathrm{mb}$ air temperature and humidity retrieved from TOVS, geostrophic winds from buoy-observed pressure fields (assumed to apply to the $850 \mathrm{mb}$ level) and radiative flux estimates derived from TOVS radiances. Free parameters are the same as those in experiment 2 .

The forcings for the three experiments are summarized in Table 1, which includes the mean and std dev. of each parameter. The fluxes computed in experiments 2 and 3 are compared to those computed in experiment 1.

\section{MODEL DESCRIPTION}

We adapted a 1-D boundary-layer model taken from the National Center for Atmospheric Research Community Climate Model Version 2 (NCAR-CCM2; Hack and others, 1993). We used only the components that compute the vertical diffusion, the surface energy balance and the subsurface thermal flux. The model is essentially a column model that extends from the bottom of the ice to either the $2 \mathrm{~m}$ or $850 \mathrm{mb}$ level in the atmosphere. The principal forcing parameters are air temperature and wind velocity at the forcing level $(2 \mathrm{~m}$ or $850 \mathrm{mb}$ ) and surface downwelling radiative fluxes. Figure 1 shows a schematic diagram of the model.

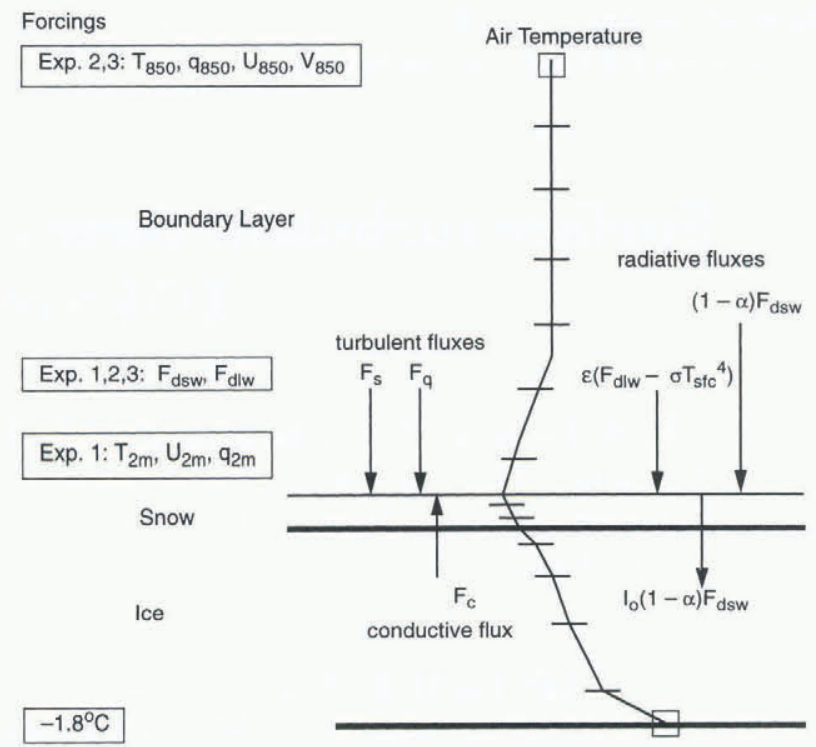

Fig. 1. Schematic of the model temperature profile and heat fluxes. The forcing parameters are the surface downwelling radiative fluxes and the air temperature and wind speed at either a height of $2 \mathrm{~m}$ (experiment 1) or at the $850 \mathrm{mb}$ level (experiments 2 and 3). There are five layers within the snow, five within the ice, and 10 within the atmospheric boundary layer.

We selected the NCAR-CCM2 model because it is well established in the scientific community, runs quickly and can be forced with the observations at hand. The adaptation of the CCM2 model leaves out the algorithm that determines radiative heating rates within the atmosphere. We discuss briefly each of the model components in turn, beginning with the ice model, then the surface energybalance model and finally the boundary-layer model.

\section{Thermodynamic ice model}

The thermodynamic ice model is in the tradition of Maykut and Untersteiner (1971). We use a version of the CCM2 subsurface thermal model that includes enhanced ice physical properties, additional ice and snow layers, and penetration of solar flux below the surface. The temperature profile is calculated by solving the thermal diffusivity equation for 10 layers with a fully implicit Crank-Nicholson scheme. Layer thickness, density, heat capacity and thermal conductivity are specified. There are five quadratically spaced layers in

Table 1. Forcings for three numerical experiments

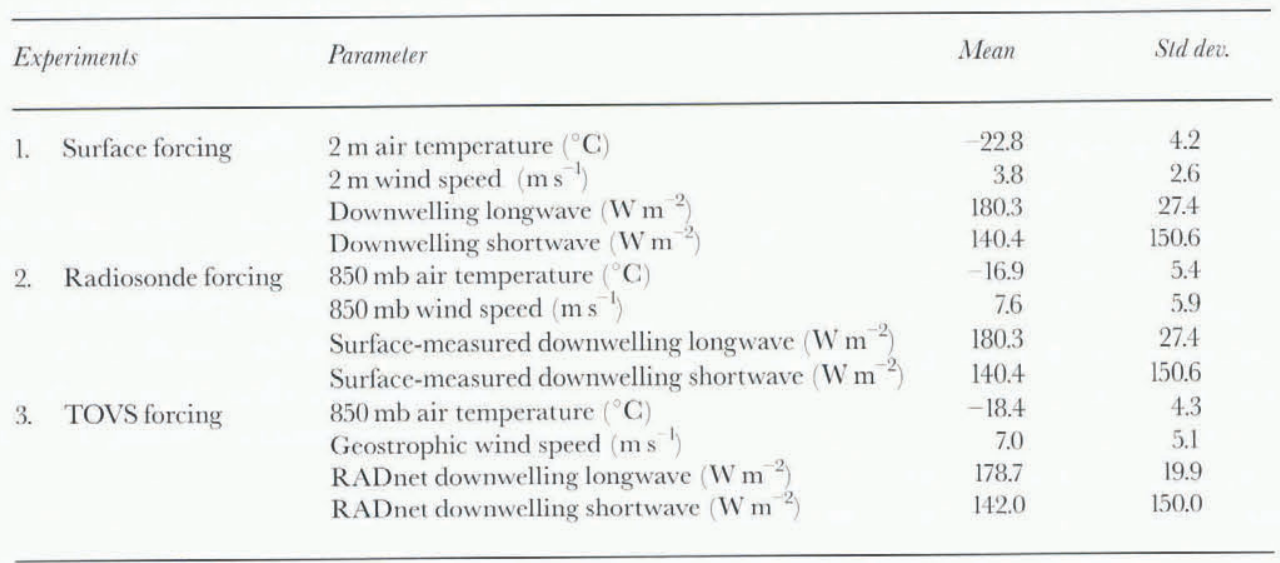


the snow and five in the ice. The top layer in the snow is $1 \mathrm{~cm}$ thick, in order to resolve fluctuations on the order of one hour (Guest and Davidson, 1994). The solar radiative flux is allowed to penetrate the surface and be absorbed throughout the snow layer, with but a small fraction entering the ice (Grenfell, 1979). Consistent with observations made at the LeadEx camp, the snow depth in the model is $10 \mathrm{~cm}$, the snow density is $400 \mathrm{~kg} \mathrm{~m}^{-3}$, the ice thickness is $3.0 \mathrm{~m}$ and the albedo is 0.80 . All four are held constant.

\section{Surface energy balance}

The terms of the energy balance for the surface layer in the snow include the net radiation, $F_{\mathrm{r}}$, the sensible heat flux, $F_{\mathrm{s}}$, the latent heat flux, $F_{\mathrm{g}}$, and the conductive flux from below, $F_{\text {c. }}$. The balance is expressed as:

$$
F_{\mathrm{r}}+F_{\mathrm{s}}+F_{\mathrm{g}}+F_{\mathrm{c}}=0
$$

All fluxes are considered positive if directed toward the surface, and the balance is zero because the top layer in the snow has negligible heat capacity and melting does not occur. The net radiation consists of both the shortwave and longwave components:

$$
F_{\mathrm{r}}=(1-\alpha) F_{\mathrm{dsw}}\left(1-I_{\mathrm{o}}\right)+\varepsilon\left(F_{\mathrm{dlw}}-\sigma T_{\mathrm{sfc}}^{4}\right),
$$

where $F_{\mathrm{dsw}}$ and $F_{\mathrm{dlw}}$ are the downwelling shortwave and longwave fluxes at the surface, $\alpha$ is the albedo of the ice, $I_{\mathrm{o}}$ is the fraction of the net shortwave flux that penetrates below the first layer, $\varepsilon$ is the surface emissivity, $\sigma$ is the Boltzmann constant and $T_{\mathrm{sfc}}$ is the surface (skin) temperature. The downwelling radiative fluxes are prescribed either from direct measurements (experiments 1 and 2) or from fluxes derived from TOVS radiances (experiment 3 ).

The sensible heat flux is determined by using a stabilitydependent exchange coefficient (Hack and others, 1993):

$$
F_{\mathrm{s}}=\rho c_{\mathrm{p}} C_{\mathrm{s}} U\left(T_{\mathrm{air}}-T_{\mathrm{sfc}}\right),
$$

where $T_{\text {sfe }}$ is the model-calculated surface (skin) temperature, $\rho$ is the air density and $c_{\mathrm{p}}$ the heat capacity. The air temperature $T_{\text {air }}$ and the wind speed $U$ is for a height of $2 \mathrm{~m}$ in experiment 1 and the midpoint of the lowest layer $(30 \mathrm{~m})$ in experiments 2 and 3 . The stress is also found using a bulk parameterization:

$$
\tau=\rho C_{\mathrm{d}} U^{2} .
$$

The transfer coefficients $C_{\mathrm{s}}$ and $C_{\mathrm{d}}$ are calculated as functions of the bulk Richardson number of the lowest layer. The latent heat is determined with the model-calculated surface-(skin) mixing ratio, and the mixing ratio determined either from the relative humidity measurements at $2 \mathrm{~m}$ (experiment $\mathrm{l}$ ) or estimated by the model for the lowest layer (experiments 2 and 3). The transfer coefficient for humidity is the same as that for sensible heat.

The $10 \mathrm{~m}$ neutral values of the heat-transfer coefficient and the drag coefficient are set to the average values measured at the camp, $C_{\mathrm{d}}=C_{\mathrm{s}}=0.0012$. Note that this measured value of $C_{\mathrm{s}}$ is corrected from that reported in Ruffieux and others (1995), based on a correction of the infrared measurements of the surface temperature. The uncertainty in the measured values of these coefficients is 0.0002 . The same coefficients are used in all three experiments.

\section{Atmospheric boundary-layer model}

The boundary-layer model is outlined in Holtslag and Boville (1993) and in Hack and others (1993). It is an explicit, non-local parameterization of the vertical fluxes of heat, moisture and momentum based on eddy diffusivities. The eddy diffusivities are the same for all three fluxes. The local diffusion scheme uses an eddy diffusivity determined independently at each point in the column, based on local vertical gradients of wind and virtual potential temperature, similar to the usual approach in global atmospheric models. The non-local scheme, used in unstable conditions only, determines an eddy-diffusivity profile based on a diagnosed boundary-layer height and a turbulent-velocity scale. It can allow for a flux directed counter to the local gradient. The major advantage of the non-local parameterization is that large eddy transport is accounted for and entrainment effects are treated implicitly.

There are 10 layers in the model. The first is centered at $30 \mathrm{~m}$, the second at $75 \mathrm{~m}$ and the rest are approximately $140 \mathrm{~m}$ thick. The boundary-layer model provides tendency terms for temperature, moisture and wind velocity at each level. Geostrophic adjustment terms are also included for the wind velocity. The model time-step is 15 minutes.

\section{FORCING PARAMETERS}

\section{Surface data}

The LeadEx ice camp occupied a multi-year ice flow from 20 March to 22 April 1992 in the Beaufort Sea, about $400 \mathrm{~km}$ north of Deadhorse, Alaska. The purpose of the experiment was to study the physical processes associated with leads in heavy pack ice. At the main camp a full set of meteorological observations was made with 15 minute averaging periods. In addition, radiosonde ascents and measurements of radiative and turbulent fluxes were made. The surface observations were reviewed by Ruffieux and others (1995). The authors report significant diurnal cycles in observed skin temperature, air temperature, relative humidity, net radiation and sensible heat flux. The wind speed was measured at a height of $3 \mathrm{~m}$, and hence the wind speed was adjusted to $2 \mathrm{~m}$ with a factor of 0.96 , based on a logarithmic wind profile. The average and std dev. of each of the forcing parameters are shown in Table 1. Figure 2 shows the $2 \mathrm{~m}$ air temperature and the $2 \mathrm{~m}$ wind speed for the period $28 \mathrm{March}$ (day 87) to $21 \mathrm{April}$ (day 111), and Figure 3 shows the downwelling shortwave and longwave fluxes. The turbulent flux measurements for the period (sensible heat and stress) are shown in Figure 4. Ruffieux and others (1995) reported that the measurement uncertainties are $\pm 2 \mathrm{~W} \mathrm{~m}^{2}$ in the sensible heat flux, $\pm 0.003 \mathrm{Nt} \mathrm{m}^{-2}$ in the stress, and $\pm 3 \mathrm{~W} \mathrm{~m}^{2}$ in the downward-longwave radiative flux. The two shortwave-flux instruments used in the field agreed to within $2 \%$ (about $10 \mathrm{~W} \mathrm{~m}^{-2}$ at midday).

\section{Radiosondes}

The radiosonde observations from the LeadEx camp and nearby shore stations were reviewed by Persson and others (1992). They reported that a well-mixed daytime boundary layer, with a depth of a few hundred meters, was common but not always present, and that the median height of the inversion base was only $28 \mathrm{~m}$. The median inversion depth was $589 \mathrm{~m}$. They also reported that low-level jets were common, and that the air in the boundary layer was often saturated with respect to ice. The ascents were made every 12 hours and hourly time-series for the $850 \mathrm{mb}$ level were gen- 

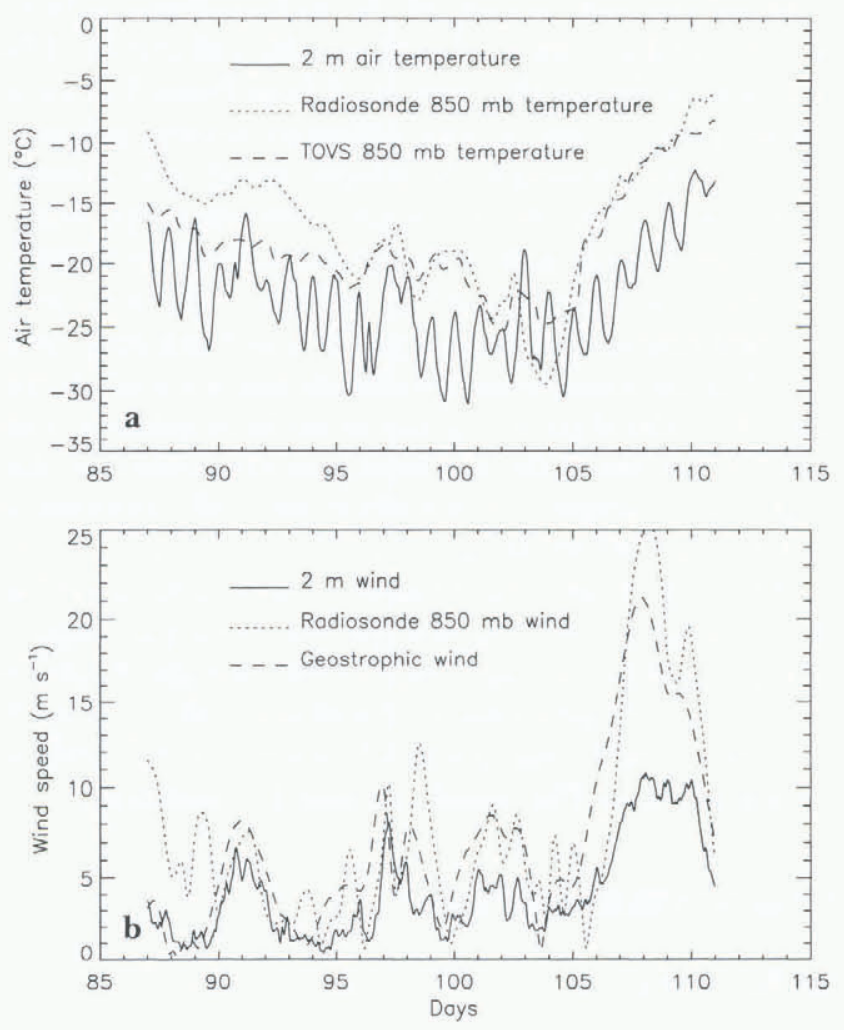

Fig. 2. Comparisons of the forcing air temperatures (a) and the forcing wind speeds $(b)$.

erated with cubic spline interpolations. The air temperature and wind speed for that level are shown in Figure 2. Note that the $850 \mathrm{mb}$ temperature averages over $5^{\circ} \mathrm{C}$ warmer than the $2 \mathrm{~m}$ temperature. The measured winds, both at
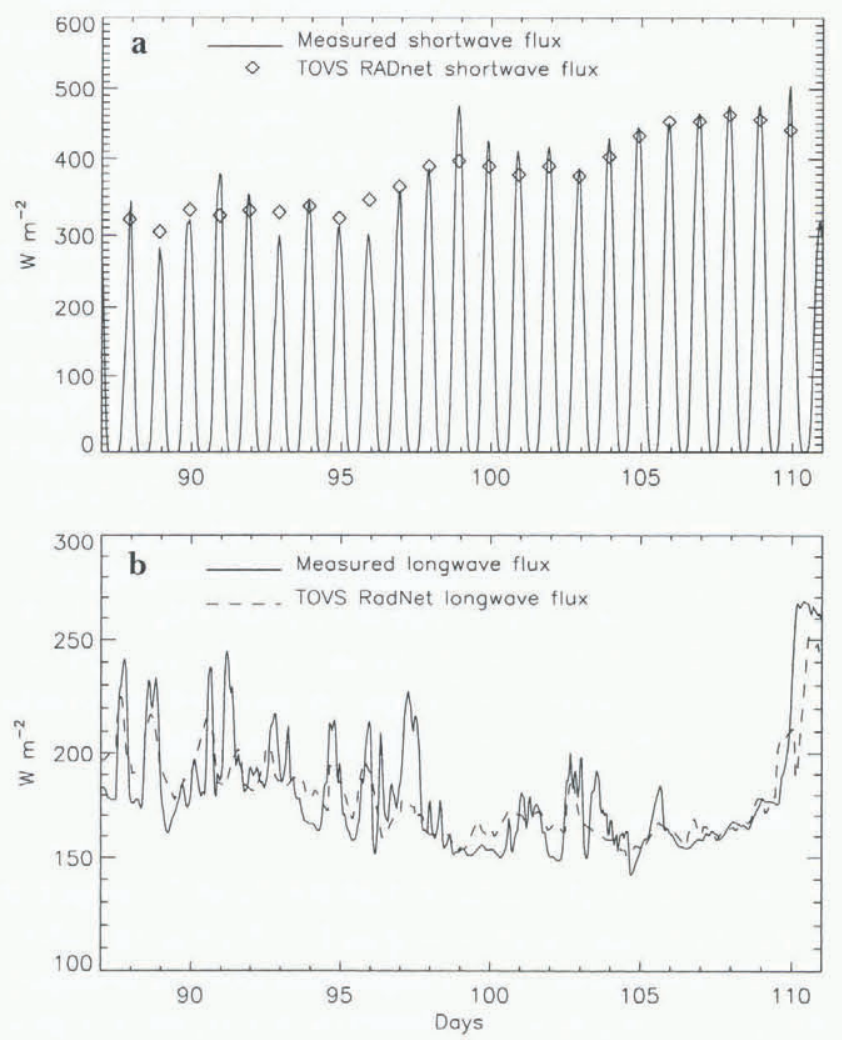

Fig. 3. Comparison of the measured downwelling radiative fluxes at the LeadEx camp to those derived from the TOVS radiances: ( $a$ ) shortwave and $(b)$ longwave. The shortwave fluxes are nearly identical because of the common solar-zenithangle dependence, so only the daily maxima in the TOVSbased estimates are plotted.
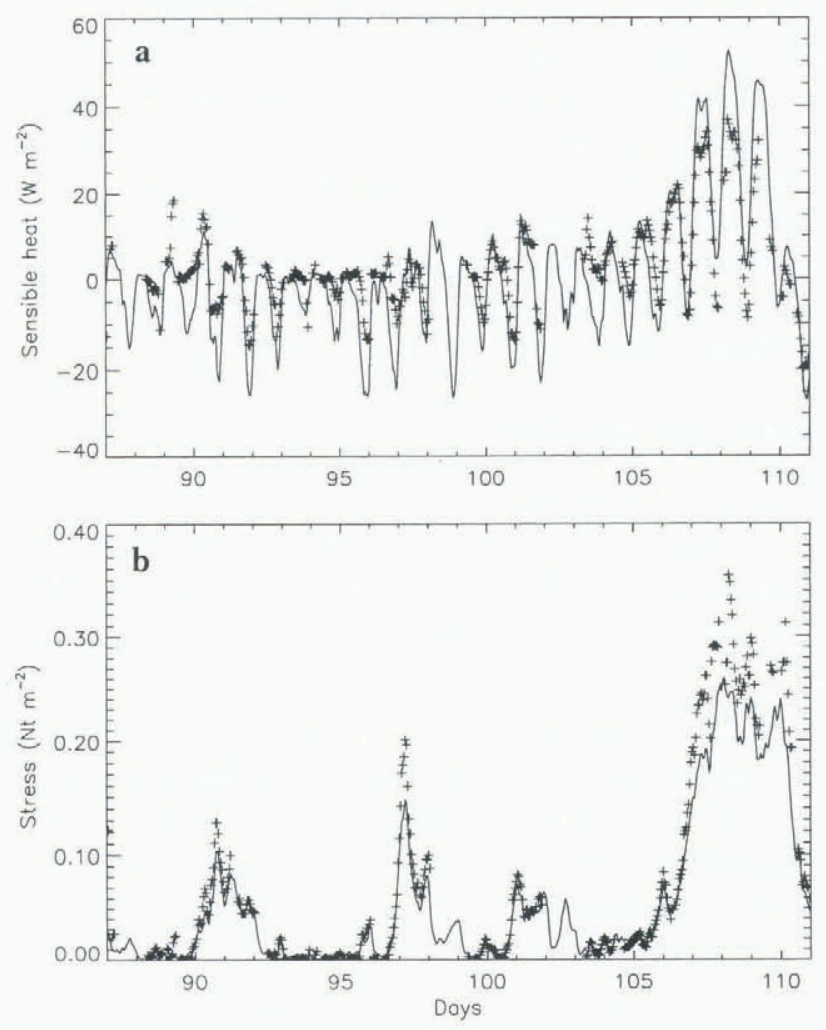

Fig. 4. Surface turbulent fluxes from experiment 1 with surface forcing (line) and from measurements (points): (a) sensible heat flux, (b) stress. The measurements are hourly averages and the model output is hourly.

the surface and aloft, indicate a high wind event in the last five days of the period. This event is accompanied by significant warming.

\section{TOVs}

The TOVS instrument comprises three radiometer arrays, two of which are used in the retrieval. The High-resolution Infrared Radiation Sounder (HIRS) has 24 channels in the visible through thermal infrared spectrum, and the Microwave Sounding Unit (MSU) has 4 channels in the $60 \mathrm{GHz}$ oxygen band. Radiances were processed with a version of the Improved Initialization Inversion (3I) algorithm (Chedin and others, 1985) that has been improved for applications in polar regions (Francis, 1994). Temperature profiles, humidity in five thick layers, cloud formation and surface skin temperature are produced for each retrieval. Daily gridded fields of the various parameters at $100 \mathrm{~km}$ resolution north of $60^{\circ} \mathrm{N}$ are produced for the NASA Pathfinder Program and are available from the National Snow and Ice Data Center. This project uses individual retrievals, not the gridded fields.

The accuracy of TOVS-derived air temperature usually decreases below $900 \mathrm{mb}$, consequently we use the retrieved $850 \mathrm{mb}$ air temperature to force the model. The wind speed at this level is assumed to be geostrophic, determined from air pressure measurements made by surface buoys. There are about 100 TOVS retrievals each day within a $200 \mathrm{~km}$ range of the ice station. A smooth time series of the various parameters is derived from these retrievals by averaging simultaneously in time and space all observations within $200 \mathrm{~km}$ of the camp that were obtained within one day of the target time. The TOVS $850 \mathrm{mb}$ air temperatures are compared to the radiosonde observations in Figure 2. The 
comparison is good except for the first eight days, when the TOVS temperature is up to $5^{\circ} \mathrm{C}$ warmer than the radiosonde measurements. This is a time of generally greater cloud cover as shown in the higher values of the downwelling longwave fluxes seem in Figure 3. The clouds may have contributed to the error in the retrieved temperature. Also seen in Figure 2 is the time series of the geostrophic wind speed determined from air pressure measurements made by buoys and interpolated by the International Arctic Buoy Program. The mean geostrophic wind speed is $7.0 \mathrm{~m} \mathrm{~s}^{-1}$ (Table 1). The $850 \mathrm{mb}$ radiosonde winds average $0.6 \mathrm{~ms}$ more than the geostrophic winds and the rms difference between them is $3.4 \mathrm{~m} \mathrm{~s}$ !

Downwelling shortwave (DSW) and longwave (DLW) radiation fluxes at the surface are obtained directly from TOVS brightness temperatures using the method developed by Schweiger and Key (1997). This method (RADnet) is based on a neural network that was trained using surface observations from the LeadEx experiment. It uses TOVS HIRS and MSU brightness temperatures as inputs and provides estimates of DLW and DSW as outputs.

The DLW fluxes were interpolated to hourly observations by averaging in time and space as discussed above. DSW observations, naturally displaying a large diurnal cycle, were interpolated to hourly values using a "solar zenith angle" weighting scheme. RADnet-computed DWS values at satellite overpass times were used to compute an "apparent cloudiness" by inverting the downwelling shortwave parameterization given by Shine (1984). This parameterization is designed to estimate the downwelling shortwave flux using the solar zenith angle, cloudiness, cloud optical depth and surface albedo. For each retrieval, the cloud fraction required to obtain the TOVS-estimated DSW in the Shine (1984) parameterization is determined using constant values for albedo and optical depth. The apparent cloudiness includes other radiative effects, such as DWS retrieval error, variable albedo and variable cloud optical depth, as well as radiative effects not included in the parameterization. This apparent cloudiness is then averaged in time and space to form an hourly time series. The hourly cloud fractions are finally used in the Shine (1984) parameterization to compute hourly DWS fluxes. The mean differences between the measured downwelling fluxes and the TOVS-derived fluxes are less than $2 \mathrm{~W} \mathrm{~m}^{-2}$. The rms differences are $16.8 \mathrm{~W} \mathrm{~m}^{2}$ for DWL and $21.3 \mathrm{~W} \mathrm{~m}^{-2}$ for DSW. The time series for both fluxes are compared to the surfacemeasured values in Figure 3 in which the DWS from TOVS is plotted only at local noon, since the TOVS-based estimate and the measured value from the camp are similar when viewed as time series.

\section{RESULTS}

We used 24 hour running mean values for numerical comparisons applied to both the measured and the modeled fluxes. We did this because the forcing values for both the radiosondes and for TOVS are derived from either twice daily samples (radiosondes) or from running 24 hour mean values (TOVS). In addition, variations on scales of $<1$ day are of limited interest for most climate studies. The mean and std dev. of the measured turbulent fluxes are shown in Table 2, in which the std dev. is indicated for hourly averages and daily averages. Times when the wind direction corre-
Table 2. Measured turbulent fluxes

\begin{tabular}{llcc}
\hline Flux & Mean & \multicolumn{1}{c}{$\begin{array}{c}\text { Sid dev. } \\
\text { hourly averages }\end{array}$} & $\begin{array}{c}\text { Sid dev. } \\
\text { daily averages }\end{array}$ \\
\hline Sensible heat $\left(\mathrm{W} \mathrm{m}^{2}\right)$ & 2.9 & 10.5 & 7.2 \\
Stress $\left(\mathrm{Ntm}^{-2}\right)$ & 0.070 & 0.090 & 0.083 \\
\hline
\end{tabular}

sponded to the direction of the camp have been excluded. Comparisons of the surface flux values from the three numerical experiments are summarized in Table 3. First, experiment 1 is compared to the measurements, then experiments 2 and 3 are compared to results from experiment 1 .

Table 3. Sensible heat flux and stress comparisons (daily averages)

\begin{tabular}{|c|c|c|c|c|}
\hline Experiment & $\begin{array}{l}\text { Nimber } \\
\text { of days }\end{array}$ & Bias & $r m s$ & $\begin{array}{l}\text { Difference } \\
\text { std der. }\end{array}$ \\
\hline \multicolumn{5}{|c|}{ Surface forcing compared to measurements } \\
\hline Sensible heat $\left(\mathrm{W} \mathrm{m}^{-2}\right)$ & 17 & -1.8 & 6.2 & 5.9 \\
\hline Stress $\left(\mathrm{N}_{\mathrm{tm}}{ }^{-2}\right)$ & 17 & 0.011 & 0.021 & 0.018 \\
\hline \multicolumn{5}{|c|}{ Radiosonde forcing compared to experiment 1} \\
\hline Sensible heat & 24 & 3.8 & 11.8 & 11.1 \\
\hline Stress $(\mathrm{N} t \mathrm{~m})^{2}$ & 24 & 0.016 & 0.052 & 0.050 \\
\hline \multicolumn{5}{|c|}{ TOVS-based forcing compared to experiment I } \\
\hline Sensible heat $\mathrm{W} \mathrm{m}^{-2}$ & 24 & 3.0 & 9.1 & 8.6 \\
\hline Stress $\left(\mathrm{N} \mathrm{m}^{2}\right)$ & 24 & -0.003 & 0.021 & 0.021 \\
\hline \multicolumn{5}{|c|}{ Geostrophic wind only, compared to experiment I } \\
\hline Stress $\left(\mathrm{Ntm}^{2}\right)$ & 24 & 0.000 & 0.033 & 0.033 \\
\hline
\end{tabular}

Figure 4 shows time series of sensible heat flux and stress for experiment 1 compared to hourly averages of the surface measurements. The diurnal cycle of the sensible heat flux is well represented, but significant biases appear in the last few days when the winds are strongest. The change in the magnitude of the differences may be associated with unknown changes in snow depth, density or albedo that are associated with the wind storm or with changes in the measurement systems. Table 3 compares the daily ( 24 hour running mean) values of the results of experiment 1 to the measurements. The bias is $-1.8 \mathrm{~W} \mathrm{~m}^{2}$. The rms difference is larger $\left(6.2 \mathrm{~W} \mathrm{~m}^{-2}\right)$, reflecting errors in the model including characterization of the surface or errors in the flux measurements. Errors in either the turbulent-flux measurements or the radiative-flux measurements would both contribute to differences between the measured and the modeled fluxes. The average model stress is $0.0011 \mathrm{Nt} \mathrm{m}^{-2}$ less than the measured stress, indicating that the reported mean value of the $10 \mathrm{~m}$ drag coefficient may have been based on a slightly different sub-set of the stress measurements. A value of $C_{\mathrm{d}}=0.014$ provides near perfect agreement, a value that is within the range of uncertainty in the reported value.

Experiments 2 and 3, which include the boundary layer, are compared to the results of experiment 1 in Figure 5 and in Table 3. In the radiosonde-based estimates of the sensible heat flux the bias and the rms difference are $3.8 \mathrm{~W} \mathrm{~m}^{2}$ and $11.8 \mathrm{~W} \mathrm{~m}^{-2}$, respectively. With the TOVS-based estimates, these differences drop to $3.0 \mathrm{~W} \mathrm{~m}^{-2}$ and $9.1 \mathrm{~W} \mathrm{~m}^{-2}$. The stress estimates are also slightly better with the TOVS-based model. The bias is $0.016 \mathrm{Ntm}^{-2}$ for experiment 2 and $0.003 \mathrm{Ntm}^{2}$ for experiment 3. The $\mathrm{rms}$ differences are 

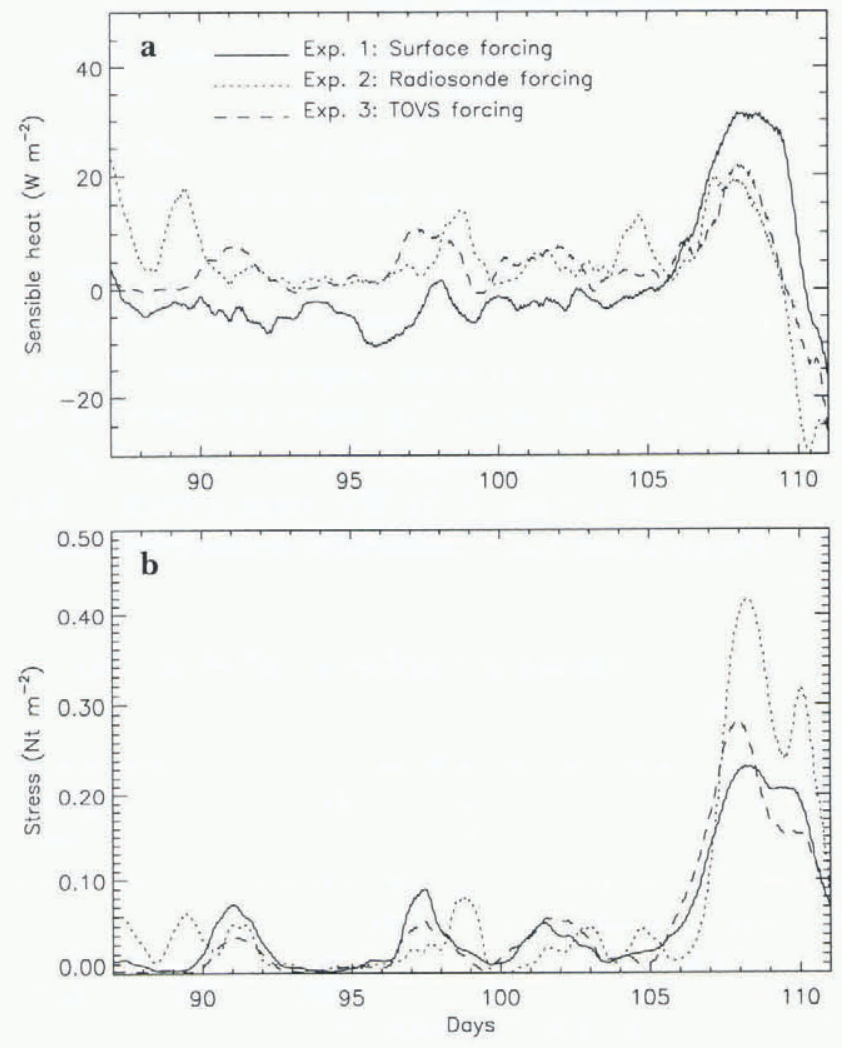

Fig. 5. Comparisons of the three numerical experiments: (a) sensible heat flux, (b) stress. The time series are 24 hour running means of the model outputs.

$0.052 \mathrm{Nt} \mathrm{m}^{-2}$ and $0.021 \mathrm{Nt} \mathrm{m}^{-2}$ respectively. The improved performance of the TOVS-based model may be due to the increased averaging (horizontal, vertical and temporal) inherent in the TOVS-based forcing. It may also reflect the presence of significant thermal wind effects that are not included in the model. These effects would make the $850 \mathrm{mb}$ radiosonde wind a poorer basis for estimating the surface stress compared to the surface geostrophic wind that is used in experiment 3 .

\section{DISCUSSION AND CONCLUSIONS}

One of our principal motivations for this study was to test a scheme in which estimates of the surface stress can account for variations in the boundary-layer stratification. How satisfactory are traditional approaches in which stratification is not accounted for? The stress in large-scale sea-ice models is often calculated with just the geostrophic wind speed $G$ and a fixed geostrophic drag coefficient $C_{\mathrm{g}}$ as:

$$
\tau=\rho C_{\mathrm{g}} G^{2}
$$

In our numerical experiments we used a measured value of the local $10 \mathrm{~m}$ drag coefficient and so, to provide a useful comparison, selected a value of $C_{\mathrm{g}}$ that gives zero bias in the stress calculated from Equation (5) when compared to the results of experiment 1 . That value is $C_{\mathrm{g}}=0.00051$. The rms difference between the experiment 1 estimates and the estimate from Equation (5) is $0.033 \mathrm{Nt} \mathrm{m}^{-2}$, compared to $0.021 \mathrm{Nt} \mathrm{m}^{-2}$ for the TOVS-based estimate (experiment 3) which also showed negligible bias. Thus the error in the TOVS-based estimate is $36 \%$ less than that found with a constant geostrophic drag coefficient. This improvement is due to the inclusion of stability effects in the boundary-layer model that influence the geostrophic drag coefficient and are determined by the surface energy balance.

In these numerical experiments, the satellite-based estimates of the stress are significantly better than estimates using a constant-drag coefficient. Because of this, we feel that a column model with TOVS-based forcing shows promise for more accurately determining the surface stress. The heat-flux estimates, on the other hand, show errors of several $\mathrm{W} \mathrm{m}^{-2}$. Only the high-wind event near the end of the period is detected, and even that is with poor accuracy. The heat flux estimates from TOVS-based forcing (Table 3) is every bit as accurate as those from radiosondes.

Experiment 1 highlights some of the difficulties in using an energy-balance model to determine the sensible heat flux. First, the net radiation must be determined, which depends both on accurate downwelling fluxes and on accurate estimates of the albedo, and second the conductive flux must be determined, which depends on an accurate estimate of the snow depth and snow density. Finally, the fluxes during LeadEx are small, often averaging over the course of one day to $<10 \mathrm{~W} \mathrm{~m}^{-2}$ in absolute value, so measuring a significant portion of their variance is difficult. Space-based estimates in the near future will probably be able to detect only the strong events such as that seen in the last six days. Although this event is detected in the TOVSbased estimates (Figure 5), significant bias remains.

The results are also sensitive to the turbulent-transfer coefficients specified. We found that if the drag coefficient and the heat-transfer coefficient were tuned independently to provide the minimum error in experiment 1 , the rms differences between the results of experiments 2 and 3 and the measurements could be made to fall below $5 \mathrm{~W} \mathrm{~m}^{-2}$ and the bias in the stress compared to the measurements made to disappear. An accurate characterization of the surface roughness will be needed to determine adequately the stress.

These experiments have shown that it is feasible to estimate surface turbulent fluxes using data collected from satellites. However, much work remains to be done before our procedure can be coupled to a two-dimensional iceocean model and fluxes can be computed on a routine basis for the entire Arctic. First, additional work needs to be conducted to select and tune the appropriate numerical model. Is the NCAR CCM2 the right one? Other models may prove more useful. Second, the results of the model are sensitive to a number of different parameters including albedo, snow depth, ice thickness and turbulent-exchange coefficients. Determining the correct values to use in the absence of in-situ data could be a formidable task. Finally, additional validation experiments should be performed for different seasons of the year and different ice conditions.

Possible enhancements to the model might include the addition of a radiative flux-divergence estimate and lead heat-flux estimates. Both would contribute to the heating rates within the boundary layer. The inclusion of clouds within the boundary layer would improve the flux divergence calculations. The sensible heat flux determined here is appropriate for thick ice. The method could be extended to other ice classes and to estimates of regional heat flux by estimating the near surface air temperature and wind speed for the dominant ice class in a region using the TOVS-based forcing and the column model described here. The nearsurface air temperature and wind speed could then be used to estimate the heat fluxes from other ice classes, including leads. 


\section{ACKNOWLEDGEMENTS}

This work was supported by the Office of Naval Research under grants N00014-96-1-0070 and N00014-91-J-1557 by NASA under grant NAGW 4169.

\section{REFERENCES}

Chedin, A., N. A. Scott, C. Wahiche and P. Moulinier. 1985. The improved initialization inversion method: a high resolution physical method for temperature retrievals from satellites of the TIROS-N series. F. Climate Appl. Meteorol., 24(2), 128-143.

Francis, J. A. 1994. Improvements to TOVS retrievals over sea ice and applications to estimating Arctic energy fluxes. 7. Geophys. Res., 99 (D5), $10,395-10,408$.

Grenfell, T. C. 1979. The effects of ice thickness on the exchange of solar radiation over the polar oceans. f. Glaciol., 22 (87), 305-320.

Guest, P.S. and K. L. Davidson. 1994. Factors affecting variations of snow surface temperature and air temperature over sea ice in winter. In Johannessen, O. M., R. D. Muench and J. E. Overland, eds. The polar oceans and their role in shaping the global environment: the Nansen Centennial volume. Washington, DC, American Geophysical Union, 435-442. (Geophysical Monograph 85.

Hack, J. J., B. A. Boville, B. P. Briegleb, J. T. Kiehl, P.J. Rasch and D. L. Wil- liamson. 1993. Description of the NCAR Community Climate Model (CCM2). Boulder, CO, National Center for Atmospheric Research. (NCAR Technical Note TN-382+STR.)

Holtslag, A. A. M. and B. A. Boville. 1993. Local versus nonlocal boundarylayer diffusion in a global climate model. f. Climate, 6 10), 1825-1842.

Maykut, G. A. 1985. An introduction to ice in the polar oceans. Seattle, WA, University of Washington. Department of Atmospheric Sciences/Geophysics Program. Applied Physics Laboratory. (Technical Report 8510.

Maykut, G. A. and N. Untersteiner. 1971. Some results from a time-dependent thermodynamic model of sea ice. f. Geophys. Res., 76 6), 1550-1575.

Overland, J. E. and K. L. Davidson. 1992. Geostrophic drag coefficients over sea ice. Tellus, 44A (1), 54-66.

Persson, P. O. G., D. Ruffieux and K. Davidson. 1992. Characteristics of the lower troposhpere during LeadEx 92. In Third Conference on Polar Meteorology, 29 September - 2 October 1992, Porlland, Oregon. Proceedings. Boston, MA, American Meteorological Socicty, 50-53.

Ruffieux, D., P. O. G. Persson, C. W. Fairall and D. E. Wolfe. 1995. Ice pack and lead surface energy budgets during LEADEX 1992. J. Geoplyys. Res., 100 C 3$), 4593-4612$.

Schweiger, A. and J. Key. 1997. Estimating surface radiation fluxes in the Arctic from TOVS HIRS and MSU brightness temperatures. Int. $\mathcal{J}$. Remote Sensing. 18, 955-970.

Shine, K. P. 1984. Parameterization of shortwave flux over high albedo surfaces as a function of cloud thickness and surface albedo. Q.J.R. Meteorol. Soc., $110(465), 747-764$. 